Platt, B. S., Miller, D. S. \& Payne, P. R. (196r). In Recent Advances in Human Nutrition, p. 35 I. [J. F. Brock, editor.] London: J. \& A. Churchill.

Platt, B. S. \& Stewart, R. J. C. (1962). Brit. F. Nutr. 16, 483.

Rabinowitz, D. \& Zierler, K. L. (1963). Nature, Lond., r99, 913.

Randle, P. J., Garland, P. B., Hales, C. N. \& Newsholme, E. A. (1963). Lancet, i, 785.

Roth, J., Glick, S. M., Yalow, R. S. \& Berson, S. A. (1963). Science, I4o, 987.

Turner, M. R. (1962). The effects of state of nutrition and pregnancy on glucose tolerance in experimental animals. M.Sc. Thesis, University of London.

Unger, R. H., Eisentraut, A. M. \& Madison, L. L. ( 1963$)$. F. clin. Invest. 42, 103 I.

van Creveld, S. (1963). Canad. med. Ass. F. 88, I.

Williams, R. H. (editor). (1960). Diabetes. New York: Hoeber.

Yoshida, A., Harper, A. E. \& Elvehjem, C. A. (1958). F. Nutr. 66, 217.

\title{
Dietary carbohydrates and lipid metabolism
}

\section{By I. Macdonald, Physiology Department, Guy's Hospital Medical School, London, $S E$ I}

The role of dietary carbohydrate in lipid metabolism has been known for some time, and this knowledge forms the basis of many agricultural practices. The conversion of carbohydrate into fat is also accepted in man and forms the mainstay of some therapeutic manoeuvres. Despite the widespread acceptance of a metabolic relationship between carbohydrate and lipid, there has been little critical analysis of this relationship. The dietary carbohydrates have been assumed to be bland constituents, all treated alike as a result of the activities of the gut and consequently, until recently, few suggestions have been made that would implicate them in disorders of lipid metabolism.

Some evidence that dietary carbohydrate may play a significant part in disease was seen in the study of kwashiorkor. The child with this malnutritional disorder not only shows the signs of protein deficiency but in addition has pathological changes which can only be due to a relative dietary excess of calories over protein, and the calories are usually supplied by carbohydrate. The large quantity of fat in the liver and the presence of reasonable quantities of depot fat mark out this malnutritional disorder from marasmus in which the child not only has a deficient protein intake but also has a similarly deficient calorie intake, the marasmic child being wasted, with no depot fat or excess liver lipid. The remarkably low serum albumin levels in kwashiorkor led to the belief that deficiency of protein was the principal dietary fault, but some experimental work in man has shown that even on a high protein intake the serum albumin is reduced by a high carbohydrate intake (Coles \& Macdonald, 1964, in preparation). Thus, calories in the form of carbohydrate may have a malevolent effect in these children. It is of interest to speculate whether it is the carbohydrate or the calories that result in the changes characteristic of kwashiorkor and therefore whether calories in the form of fat would also result in the same clinical picture.

\section{Experiments on animals}

In an attempt to understand the effects of dietary carbohydrates on lipid metabolism, rabbits were placed on diets so arranged that the protein intake was kept constant but the carbohydrate (and thereby the calorie) intake varied. The results 
showed that the animals with the relative excess of dietary carbohydrate lost weight more rapidly, and their livers became fatty. Also, the concentration of total serum proteins fell more rapidly in the animals eating the relative excess of dietary carbohydrate (Macdonald \& Gharavi, I960). The changes in the extent of the liver fat had been described earlier in rats (Best, Hartroft, Lucas \& Ridout, I949) and in pigs (Heard, Platt \& Stewart, 1958) in which the serum protein level also fell to a greater extent with an increase in intake of carbohydrate.

\section{Observations on children}

More detailed examination of the lipids in the depot fat and livers of children with kwashiorkor revealed that the increase in lipid in the liver was mainly as glycerides and phospholipids, with no increase in sterol esters, and the fatty acid pattern changed in a similar way in both liver and depot fat (Macdonald, I963). Examination of the serum lipids during recovery from kwashiorkor showed a marked rise in the glycerides followed by a fall to normal levels in about 3 weeks. Evidence was also obtained at the same time which made it unlikely that the accumulation of lipid in the liver was from the adipose tissue (Macdonald, Hansen \& BronteStewart, 1963 ).

Thus it seems that a relative excess of dietary carbohydrates, at least in conjunction with a low protein intake, can in children and experimental animals give rise to derangement of lipid metabolism.

\section{Different responses to various dietary carbohydrates}

It has been tacitly assumed until fairly recently that all dietary carbohydrates exert the same influence on lipid metabolism. This is now known to be incorrect, largely as a result of studies of effects of various dietary carbohydrates on serum cholesterol levels in the rat (Portman, Lawry \& Bruno, 1956), rabbit (Grant \& Fahrenbach, 1959), chick (Grant \& Fahrenbach, 1957) and germ-free chick (Kritchevsky, Kolman, Guttmacher \& Forbes, 1959). The level of serum cholesterol in the cebus monkey was not, however, influenced by the substitution of sucrose for starch in the diet (Portman, Hegsted, Stare, Bruno, Murphy \& Sinisterra, 1956). The different influences of various dietary carbohydrates on growth have also been reported in the rat (Harper \& Katayama, 1953) and in the chick (Monson, Dietrich \& Elvehjem, 1950). In all these accounts of different effects, sucrose is the carbohydrate that seems to be associated with the highest level of serum cholesterol, and with the least growth.

To compare the effects of various carbohydrates on the amount and composition of liver and depot fat, adult rabbits were given a constant protein intake with different amounts of various carbohydrates. The results of these experiments showed that the amount of liver lipid was directly related to the mean daily carbohydrate intake. Also, weight for weight, sucrose was associated with more liver lipid than was liquid glucose BPC (a partial hydrolysate of starch), and the latter with more liver lipid than starch. Variations in the intake of sucrose and liquid glucose were associated with corresponding variations in cholesterol in the liver (Macdonald, 1962). 


\section{Experiments on man}

The translation of these findings to man cannot be done with certainty and, therefore, the experimental subject must be man in order to assess the relevance of the animal work. In 1960 it was found that diets containing carbohydrates of fruits, vegetables and legumes produced lower serum cholesterol values than those containing the same number of calories supplied by sucrose and milk sugar (Keys, Anderson \& Grande, I960).

In this laboratory an experiment was undertaken on seven adult males which consisted of eating daily $500 \mathrm{~g}$ of one type of carbohydrate for 25 days with protein in the form of lean meat and with green vegetables and water-preserved fruit. After an interval the dietary régime was repeated with a change in the type of carbohydrate used. The two carbohydrates used were maize starch and sucrose. Weekly samples of fasting serum lipid and depot fat were analysed during the time on the diet (Macdonald \& Braithwaite, 1964). The starch diet caused a fall in the level of the serum lipids whereas the sucrose diet produced a rise. The levels of sterol esters and phospholipids in the serum were reduced when the starch diet was given but were not altered by the sucrose diet. The glyceride level was not affected by the starch diet but rose on the sucrose diet (Table I). Changes were also noticed in the fatty acid pattern of the serum and depot lipids and are summarized in Table 2. There was also some evidence in these experiments compatible with the production of liver damage while the subjects were on the starch diet.

Table I. Changes in the concentration of serum lipid and its fractions found in adult males on a diet low in fat and high in starch or sucrose

$\begin{array}{llc} & \text { Starch diet } & \text { Sucrose diet } \\ \text { Total serum lipid } & \text { Decreased } & \text { Increased } \\ \text { Sterol esters in serum } & \text { Decreased } & \text { Unchanged } \\ \text { Glycerides in serum } & \text { Unchanged } & \text { Increased } \\ \text { Phospholipid in serum } & \text { Decreased } & \text { Unchanged } \\ \text { Total cholesterol in serum } & \text { Decreased } & \text { Unchanged }\end{array}$

Table 2. Changes in the fatty acid pattern in the serum and depot lipids in adult males on a diet low in fat and high in starch or sucrose

\begin{tabular}{|c|c|c|c|c|}
\hline \multirow[b]{2}{*}{ Fatty acid } & \multicolumn{2}{|c|}{ Serum lipid } & \multicolumn{2}{|c|}{ Depot fat } \\
\hline & Starch diet & Sucrose diet & Starch diet & Sucrose diet \\
\hline Myristic & - & - & Unchanged & Unchanged \\
\hline Palmitic & Increased & Increased & Unchanged & Unchanged \\
\hline Palmitoleic & Unchanged & Unchanged & Unchanged & Decreased \\
\hline Stearic & Unchanged & Unchanged & Unchanged & Unchanged \\
\hline Oleic & Increased & Unchanged & Increased & Increased \\
\hline Linoleic & Decreased & Decreased & Decreased & Unchanged \\
\hline
\end{tabular}

Acne was traditionally considered by the dermatologist to be associated with a high carbohydrate intake (Barber, I930) and treatment was directed towards lessening the carbohydrate intake. With this empirical treatment in mind, the fatty acid composition of the sebum on the skin of the face was studied in the men while on 
the diets described above. Some of the fatty acid proportions were changed by the high-carbohydrate diets and the pattern of the change was not the same for starch as it was for sucrose. There may be, therefore, some metabolic justification for the therapy of reducing the intake of carbohydrates in certain skin disorders, and the skin lesions in kwashiorkor may be, in part, the product of the carbohydrate.

One of the results of exercise is an alteration in the serum lipid level, depending on the nature and duration of the exercise (Kontinnen, 1959). Since the nature of the diet during exercise may also influence the serum lipids the opportunity was taken of studying the effect of exercise while the subjects were consuming one of two types of carbohydrate. The exercise was the 55 mile walk from London to Brighton by medical students. It was found that after walking 27 miles the students who ate glucose only had a significantly lower serum cholesterol than those eating sucrose. This difference was even more marked after 55 miles walking (Macdonald, I964, in preparation).

\section{Possible causes for metabolic differentiation of dietary carbohydrates}

One possibility for the differences in lipid response observed may be that glucose does not follow the same metabolic pathway as fructose. Against this argument is the response by the liver to liquid glucose BPC, the amount of lipid found being intermediate between the amounts found when starch and sucrose were given (Macdonald, r962). As liquid glucose BPC, when hydrolysed, gives glucose molecules only the response should have been similar to that with starch if the different metabolic handling of fructose was the explanation. Also rats given sucrose, glucose or fructose as the dietary carbohydrate had serum cholesterol levels that were not significantly different (Portman, Lawry \& Bruno, 1956).

Can the explanation lie in the influence of these carbohydrates on intestinal microflora? In support of this hypothesis are the findings that the intestinal microflora is influenced by the type of dietary carbohydrate (Peterson, Dick \& Johansson, I953) and that the fall in serum cholesterol level in rats on a high-starch diet is eliminated when a poorly absorbed antibiotic is given (Portman, Lawry \& Bruno, 1956). The hypocholesterolaemic effect of glucose in chickens is reduced by the addition of an antibiotic to the diet (Kritchevsky, Grant, Fahrenbach, Riccardi \& McCandless, I 958). If this hypothesis is accepted then it is difficult to explain the fact that the reduction in serum cholesterol after about $7 \mathrm{~h}$ walking is greater when glucose is eaten than when sucrose is eaten. It is unlikely that any great change in gut microflora could have occurred in this relatively short time.

There is, at the moment, no adequate explanation for the different effects of dietary carbohydrates on lipid metabolism, nor any convincing leads as to the site of the metabolic differentiation. Dietary carbohydrates, it can be concluded, do exert an influence on lipid metabolism; the extent of this influence is largely unknown, as are the metabolic pathways involved. However, it is quite clear that their effect is not negligible either as a group or as individual substances. The clinical significance of these findings must await further knowledge. 


\section{REFERENCES}

Barber, H. W. (1930). In Taylor's Practice of Medicine, p. 937. [E. P. Poulton, editor.] London: J. \& A. Churchill.

Best, C. H., Hartroft, W. S., Lucas, C. C. \& Ridout, J. H. (1949). Brit. med. 7. ii, roor.

Grant, W. C. \& Fahrenbach, M. J. (1957). Fed. Proc. 16, 50.

Grant, W. C. \& Fahrenbach, M. J. (1959). Proc. Soc. exp. Biol., N.Y., roo, 250.

Harper, A. E. \& Katayama, M. C. (1953). F. Nutr. 49, 26 I.

Heard, C. R. C., Platt, B. S. \& Stewart, R. J. C. (I958). Proc. Nutr. Soc. r7, xli.

Keys, A., Anderson, J. T. \& Grande, F. (r960). Y. Nutr. 70, 257.

Kontinnen, A. (1959). Ann. Med. exp. Fenn. 37, Suppl. 7.

Kritchevsky, D., Grant, W. C., Fahrenbach, M. J., Riccardi, B. A. \& McCandless, R. F. J. (I958), Arch. Biochem. Biophys. 75, 142.

Kritchevsky, D., Kolman, R. R., Guttmacher, R. M. \& Forbes, M. (1959). Arch. Biochem. Biophys. 85, 444 .

Macdonald, I. (I962). Y. Physiol. 162, 334.

Macdonald, I. (1963). Amer. F. clin. Nutr. 12, 43 I.

Macdonald, I. \& Braithwaite, D. M. (1964). Clin. Sci. (In the Press.)

Macdonald, I. \& Gharavi, E. M. (1960). Proc. Nutr. Soc. 19, xxix.

Macdonald, I., Hansen, J. D. L. \& Bronte-Stewart, B. (1963). Clin. Sci. 24, 55.

Monson, W. J., Dietrich, L. S. \& Elvehjem, C. A. (1950). Proc. Soc. exp. Biol., N. Y., 75, 256.

Peterson, G. E., Dick, E. C. \& Johansson, K. R. (1953). F. Nutr. 5x, I 7 I.

Portman, O. W., Hegsted, D. M., Stare, F. J., Bruno, D., Murphy, R. \& Sinisterra, I. (1956). 7. exp. Med. 104, 8I 7 .

Portman, O. W., Lawry, E. Y. \& Bruno, D. (1956). Proc. Soc. exp. Biol., N.Y., gr :32 I.

\section{Nutritional consequences of altered carbohydrate absorption in infancy and childhood}

\section{By A. Holzel, Department of Child Health, University of Manchester}

For the breast-fed infant, which is now a rarity, but also for the bottle-fed baby, carbohydrates provide approximately $50 \%$ of the total calorie requirements. These are, initially at least, entirely disaccharides, namely lactose and sucrose. Later on when cereals are introduced into the diet another disaccharide, maltose, has an equally important role. The starch in the cereals is broken down by amylase to maltose and the latter by maltose-splitting enzymes to glucose which is then further metabolized. Thus the three most important disaccharides are lactose, sucrose and maltose. They are not hydrolysed in the intestinal lumen as had been believed for a long time, but are transported through the wall of the mucosal cells, and hydrolysis takes place inside these cells whence they pass as monosaccharides into the portal circulation. Dahlquist \& Borgström ( $196 \mathrm{r}$ ) established these facts only during recent years, but they have to a large extent already been confirmed by a number of other workers. According to the Swedish workers, carbohydrase action is not uniformly distributed over the whole of the small intestines, but is mainly concentrated in the jejunum although some activity can also be found in the ileum.

Lactase activity seems to be located in the duodenum and in the proximal part of the jejunum. A personal observation supports this finding. A newborn infant who was operated on for an exomphalos and was also found to have an atresia of the ileum showed an excellent response to a lactose loading test. 